\title{
Balance between education- and research-oriented publications from a Brazilian University Hospital
}

\section{K. Mendonça de Araujo ${ }^{1}$, \\ P.A.S. Mourão ${ }^{2,3}$ and J. Leta ${ }^{1}$}

\author{
${ }^{1}$ Programa de Educação, Gestão e Difusão em Biociências, Instituto de Bioquímica \\ Médica, Centro de Ciências da Saúde, Universidade Federal do Rio de Janeiro, \\ ${ }^{2}$ Programa de Glicobiologia, Instituto de Bioquímica Médica, Centro de Ciências da \\ Saúde, Universidade Federal do Rio de Janeiro, \\ ${ }^{3}$ Laboratório de Tecido Conjuntivo, Hospital Universitário Clementino Fraga Filho, \\ Centro de Ciências da Saúde, Universidade Federal do Rio de Janeiro, \\ Rio de Janeiro, RJ, Brasil
}

\author{
Correspondence \\ J. Leta \\ Instituto de Bioquímica Médica \\ CCS, UFRJ \\ Bloco B, Sala 39 \\ 21941-590 Rio de Janeiro, RJ \\ Brasil \\ E-mail: jleta@bioqmed.ufrj.br \\ Research supported by CNPq and \\ FAPERJ. K. Mendonça-Araujo is the \\ recipient of an undergraduate \\ fellowship from FAPERJ.
}

Received October 27, 2004 Accepted March 22, 2005

\begin{abstract}
We analyzed the trends of scientific output of the University Hospital, Federal University of Rio de Janeiro. A total of 1420 publications were classified according to pattern and visibility. Most were nonresearch publications with domestic visibility. With time, there was a tendency to shift from non-research (or education-oriented) publications with domestic visibility to research publications with international visibility. This change may reflect new academic attitudes within the institution concerning the objectives of the hospital and the establishment of scientific research activities. The emphasis of this University Hospital had been on the training of new physicians. However, more recently, the production of new knowledge has been incorporated as a new objective. The analysis of the scientific production of the most productive sectors of the hospital also showed that most are developing non-research studies devoted to the local public while a few of the sectors are carrying out research studies published in journals with international status. The dilemma of quality versus quantity and of education versus research-oriented publication seems, however, to continue to exist within the specialized sectors. The methodology described here to analyze the scientific production of a university hospital can be used as a tool to better understand the evolution of medical research in Brazil and also to help formulate public policies and new strategies to include research among the major objectives of University Hospitals.
\end{abstract}

\section{Introduction}

The development of the Brazilian scientific and technological infrastructure as well as the training and expansion of the scientific community are recent events when compared with developed nations (1). For the
Key words

- University Hospital

- Scientific publications

- Publication visibility

- Pattern of publications

- Bibliometrics medical sciences, the turning point in this process was the foundation of the Oswaldo Cruz Institute in the city of Rio de Janeiro in the early 1900's. For decades, this institute was the main Brazilian institution devoted to medical research. The scientific research developed there was led by Oswaldo Cruz 
and Carlos Chagas, two of the most important Brazilian medical scientists. At that time, the Institute achieved international recognition due mostly to its organizational model based on teaching and research activities, which were carried out with intense exchange with foreign scientists. Despite its scientific recognition, Brazilian society was inclined to give the Institute exclusive recognition for its production of vaccines and the implementation of several preventive measures for the control of infectious diseases $(2,3)$.

In the late 1900's, a remarkable expansion of research in the medical sciences occurred, mostly as a consequence of the establishment of research in the major Brazilian public universities. This process, however, was not uniform among the various regions of the country or in the two economically and politically leading States, São Paulo and Rio de Janeiro. Since 1930, following international trends, the Medical School of the University of São Paulo (USP, and its University Hospital) had been involved in teaching, social assistance and research. Similarly, research was also included as a major objective of a new state Medical School, on a new campus of USP created in 1948 in the city of Ribeirão Preto, State of São Paulo (4).

A different scenario took place in the State of Rio de Janeiro. Although the first Brazilian university was founded in Rio de Janeiro in 1920 (University of Brazil, now Federal University of Rio de Janeiro, FURJ), medical research was not implemented in its Medical School until the 1990's. The gap in the implementation of medical research between FURJ and USP was the result of at least three factors. First, for decades the training of physicians was dispersed among general hospitals since there was no central University Hospital in the State of Rio de Janeiro. Second, the scientific success of the Oswaldo Cruz Institute had attracted students from medical schools and physicians interested in medical research. This situa- tion reinforced the false concept that the major function of a medical school should be to train students for medical practice, while specific institutes should be responsible for carrying out research. Finally, changes in the academic organization of the Brazilian universities seem to have had a more intense impact on FURJ, leading to a clear separation between the clinical and biomedical sciences. The latter was remarkably developed in terms of research through the last decades of the 1900's while clinical sciences continued to be devoted mainly to medical training.

At the end of the 1970's, a university hospital called "Hospital Universitário Clementino Fraga" but referred to here as University Hospital of the Federal University of Rio de Janeiro, was finally founded at FURJ (5). At the beginning, as an extension of the medical school, the university hospital's main goal was to develop routine medical practice in such a way that the students would have appropriate training. Therefore, the major goal of this new unit was closely related to teaching and medical care, without emphasis on research. This policy lasted until 1990, when the Scientific Research Commission (SRC) was established as a new sector of the University Hospital.

The purpose of SRC was to stimulate, support and record research activity within the University Hospital. Since its foundation, SRC has been offering financial compensation to those who publish books, chapters or papers in national or international journals or participate in scientific meetings. SRC has also established a well-organized system to collect and catalogue information on the scientific literature published by the academicians of the University Hospital. The database organized by the SRC permits an in-depth detailed analysis of the implementation of medical research within the university hospital, which has been slowly expanding within the institution. However, different concepts concerning the meaning of both 
research itself and the policy for publication still co-exist among the university hospital's staff. Should the hospital's publication policy give more importance to research articles aimed at international scientific peers or should it assign more value to educationoriented publications directed to a domestic public?

In the present paper, we analyze the trends of the publications originating from the University Hospital of FURJ. The information presented here may not only be useful to follow the establishment of a research structure within a single university hospital, but may also have general implications for the understanding of the various philosophies that co-exist in Brazilian medical institutions.

\section{Methodology used to analyze the scientific productivity of the University Hospital, FURJ}

The 1420 publications registered at SRC were classified into three types: 1) publications with international visibility, including those written mainly in English and published in journals indexed by one or both of the two international databases searched, i.e., Web of Science and PubMed (6,7); 2) publications with some international visibility, including publications written mostly in Portuguese and indexed by the Brazilian database, Scientific Electronic Library Online (8), but not by the two international databases mentioned above, and 3) publications with mostly domestic visibility. The last group includes publications written in Portuguese but not indexed by any of the three databases. The publications classified into the third group, mostly domestic visibility, were divided into four categories: books, chapters in books, articles published in nonindexed periodicals, and others (a residual category).

According to the classification established by Pincus et al. (9), the publications regis- tered at SRC are classified as: 1) research, 2) review, 3) case report, 4) opinion, and 5) others (residual category).

\section{Publications from the University Hospital, FURJ - what is the type of article it intends to publish? What is the type of reader it intends to reach?}

In the 1990-2002 period, 1420 publications (including articles, books and chapters in books) were registered at SRC by the staff (physicians and academicians) of the University Hospital, FURJ. Most of them mainly had domestic visibility (822 publications, $58 \%$ of the total). Publications with international visibility accounted for $27 \%$ of the total $(\mathrm{N}=382)$. Five hundred and nine of the 948 articles were classified as research while 650 were classified as non-research-oriented articles (case reports, reviews, opinion, others). Books and chapters in books, non-research-oriented publications, corresponded to a total of 262. Research articles were the most frequent publications among those with international visibility. Case reports and reviews, however, were more common among those with some international visibility, while books were the most frequent form of publication among those with domestic visibility. Thus, the preponderance of non-research publications in the University Hospital reflects its historical orientation, mostly related to the training and improvement of physicians and other health professionals, rather than to the production and dissemination of new knowledge among peers (data not shown).

Analysis of the trends of the University Hospital's publications with different visibility and classification is shown in Figure 1. Publications classified as research and those with international visibility increased at a similar rate during the last 12 years (Figure 1A). A similar tendency was also observed for publications with a non-research 
focus, i.e., education-oriented publications (case reports, reviews, opinions, and others), and those with domestic visibility (Figure 1B). The two variables grew markedly from 1990 to $1993(\mathrm{r}=0.97)$, tending to stabilize thereafter $(r=0.04)$, except for an unusual peak in 2000 (excluded from the analysis). Hence, the data suggest changes in the academic concepts of the University Hospital. As described previously, most of the publications are directed at the local public, who looks for updated information on important issues in medicine and health sciences (education-oriented publications). However, as new scientific groups emerged at the University Hospital, the production of new knowledge and the tendency to publish in international journals seem to have slowly increased. At this point, peers have become the major readers.

\section{Publications from the different sectors of the University Hospital - quality versus quantity, is it still a dilemma?}

The University Hospital of FURJ is organized into different specialized sectors, as is

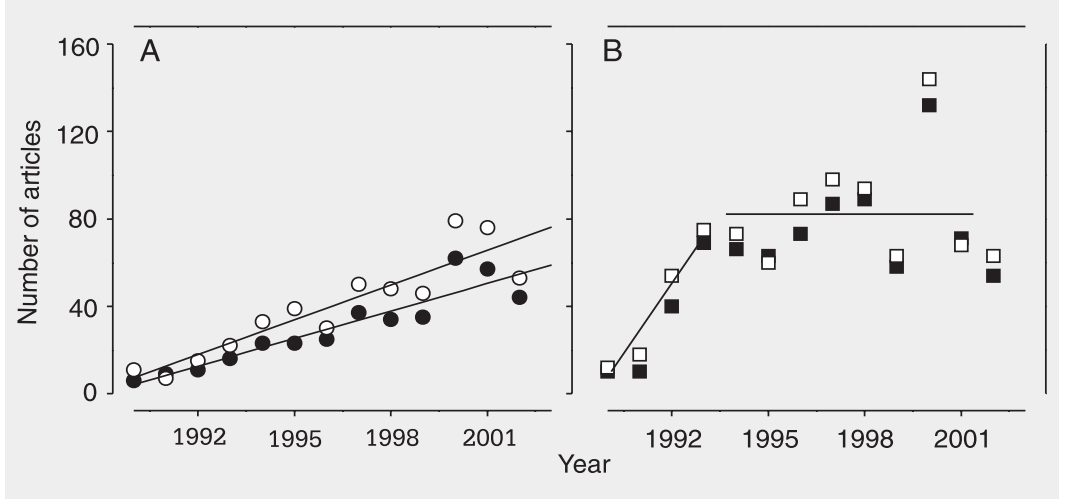

Figure 1. Number and visibility of research- and education-oriented publications originating from the University Hospital of the Federal University of Rio de Janeiro from 1990 to 2002. Source: Scientific Research Commission. Panel $A$ shows the number of research-oriented publications (open circles) and those with international visibility (filled circles). Panel $B$ shows education-oriented publications (filled squares) and those with domestic visibility only (open squares). The lines in panel A were calculated as linear regressions, and linear coefficients of 0.909 and 0.928 were calculated for values of increasing numbers of research articles and those with international visibility, respectively. the case for most medical institutions. In order to evaluate how the education- and research-oriented publications are distributed inside the institution, we analyzed the productivity of each sector. One of our first findings was that the ten most productive sectors were responsible for $75 \%$ of the total of 1420 publications published in the 19902002 period. Among these sectors, dermatology is the one with the largest share of publications $(13 \%)$, while hematology and cardiology are those with the lowest share (4 and $3.6 \%$, respectively). Analysis of the visibility and classification of the publications in the various sectors, however, revealed a different distribution: hematology was the sector that mostly published research-oriented publications with international visibility, while dermatology was among the sectors that mostly published education-oriented publications with domestic visibility. This relationship, however, was not generally observed among the different sectors. One example is radiology, which has published mostly research-oriented publications but with low international visibility (data not shown).

The relationship between type of publication, visibility and total publications for the ten most productive sectors is shown in Figure 2. Clearly, there is no correlation between total number of publications and research-oriented publications (Figure 2A) or between total number of publications and international visibility (Figure 2B). In contrast, a close correlation is observed both between research-oriented publications and international visibility (Figure 2C) and between education-oriented publications (nonresearch publications) and domestic visibility (Figure 2D). From this analysis, we conclude that publications originating from the hematology, pneumology, infectious diseases, and neurology sections are mostly research-oriented and are found in journals with international visibility. On the contrary, those from the dermatology, radiology, en- 
docrinology, and surgery sections are mostly education-oriented publications with domestic visibility.

For comparative purposes, the data regarding the scientific productivity of three research laboratories ("Laboratório Multidisciplinar", "Programa Avançado de Biologia Celular Aplicada à Medicina" and "Laboratório de Tecido Conjuntivo") were also added to Figure 2 (open circles). These laboratories were set up in the hospital during the last 5 years and are not associated with its traditional, specialized clinical sectors. They did not account significantly for the overall scientific production of the hospital, espe- cially due to their recent installation. However, their scientific productivity differs from that of the other sectors, with a ratio of approximately $1: 1$ between total publication and international visibility (Figure 2A) and between research-oriented publications and international visibility (Figure 2C). The trends observed for these laboratories definitely exemplify the trends of productivity expected for a scientific unit.

\section{Future perspectives}

About $86 \%$ of the in-house practical training in Brazil is concentrated in university
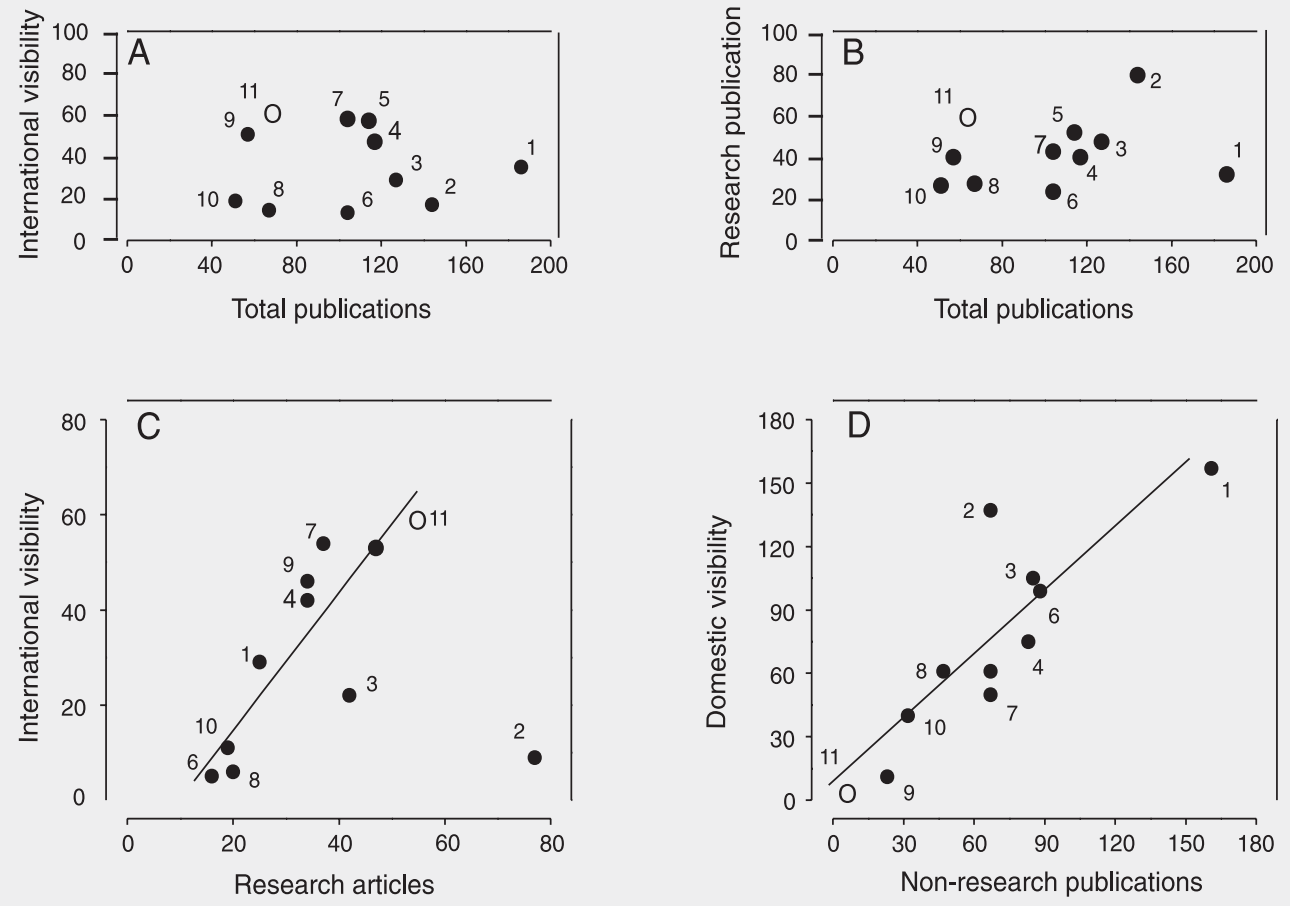

Figure 2. Relationship between types of publications, visibility and total number of publications from the 10 most productive sectors of a University Hospital. The panels correlate research-oriented publications versus total publication (A), international visibility versus total publications (B), international visibility versus research-oriented publications (C), and domestic visibility versus education-oriented publications (D) of the specialized sectors of the university hospital. The sum of the publications of the three basic research laboratories installed in the hospital is also indicated by the symbols. The lines in panels $C$ and $D$ were calculated as linear regressions, and linear coefficients of 0.975 and 0.886 were calculated for the values in panels $C$ and $D$, respectively. The scientific productivities of radiology and of the basic research laboratories were not considered in the calculation of the linear regressions. 1) Dermatology; 2) radiology; 3) endocrinology; 4) infectious diseases; 5) pneumology; 6) surgery; 7) neurology; 8) community support service; 9) hematology, 10) cardiology, and 11) publications from three research laboratories (open circles). 
hospitals $(10,11)$. Its importance for medical care, especially regarding more complex procedures, has been clearly highlighted (1214). However, studies on the scientific activity and publication types of these institutions are still scarce. A previous study discussed the relationship between the amount of funds granted by research agencies to the research laboratories of the University of São Paulo Medical School and their scientific productivity (15). However, this study contains no information on the visibility or types of the publications.

The lack of appropriate data makes it hard to compare our results with those for other Brazilian hospitals or foreign institutions. Although studies with international visibility are easily accessed using the various databases, publications with domestic visibility are dedicated mostly to a local public and are not so easily available. In order to attempt some comparison, we are now starting to analyze the scientific literature published by the Department of Internal Medicine of the Ribeirão Preto School of Medicine (Mendonça de Araujo K, Mourão PAS and Leta J, unpublished data), a campus of USP. Preliminary analysis indicates some contrasts between the scientific output of this institution and that of the University Hospital of FURJ. It also points out different academic concepts for the meaning of research in a University Hospital. Certainly, such differences are a consequence of complex social and historical factors, including the peculiarities of the scientific workforce of the two institutions which is directly in- volved in scientific activities.

The University Hospitals concentrate most of the in-house practical medical training (11). They should also be understood as centers that play an important role in medical care, that concentrate human, physical and financial resources, and that play an important role within the communities by helping to dictate their health policies. In addition, they should also be understood to be institutions where teaching, assistance and research activities must be closely associated, thus attracting young and creative students who may be driven to research activity. This strategic action would help the country to face new challenges in medicine, such as the use of molecular- and cell-based techniques for the diagnosis, treatment and control of diseases. The expansion of the present study to other medical institutions may help us not only to clarify the historical evolution of medical research in Brazil but also to outline new strategies to increase research in university hospitals.

\section{Acknowledgments}

The authors are grateful to Drs. Vivian Rumjanek and Maria Christina Mello for their comments and revision of the manuscript. The authors are also grateful to Haroldo Luiz Saback de Macedo and João Alberto Correia, who kindly made the database of the University Hospital available, and to Adriana A. Piquet for helping to elaborate the figures and the statistical analysis of some of the data.

\section{References}

1. Schwartzman S (1979). Formação da Comunidade Científica no Brasil. Editora Nacional/Finep, São Paulo, SP, Brazil.

2. Weltman WL (2002). A produção científica publicada pelo Instituto Oswaldo Cruz no período 1900-17: um estudo exploratório. História, Ciências, Saúde, 9: 159-186.

3. Stepan N (1976). Gênese e Evolução da Ciência Brasileira. Editora Artenova S.A., Rio de Janeiro, RJ, Brazil.
4. Campos ES (2004). História da Universidade de São Paulo. Editora EDUSP, São Paulo, SP, Brazil.

5. A implantação do Hospital Universitário da UFRJ. Hospital Universitário Clementino Fraga Filho page. [http://www.hucff.ufrj.br/ int_frame.php?pag=conheca/index.htm]. Accessed February 2004.

6. ISI Web of Knowledge. The Thompson Corporation page [http:// isi3.newisiknowledge.com/portal.cgi?DestApp=JCR\&Func=Frame]. 
Accessed October 2003.

7. PubMed. The National Library of Medicine page [http://www. ncbi.nlm.nih.gov/entrez/query.fcgi]. Accessed October, 2003.

8. SciELo. The Scientific Electronic Library Online page [http://www. scielo.br/]. Accessed October 2003.

9. Pincus HA, Henderson B, Blackwood D \& Dial T (1993). Trends in research in two general psychiatric journals in 1969-1990: research on research. American Journal of Psychiatry, 150: 135-142.

10. Campos GWS (1999). Educação médica, hospitais universitários e o sistema único de saúde. Caderno de Saúde Pública, 15: 187-194.

11. Médici AC (2001). Hospitais universitários: passado, presente e futuro. Revista da Associação Médica Brasileira, 47: 149-156.

12. MS, Ministério da Saúde, Secretaria de Gestão do Trabalho e da Educação na Saúde, Departamento de Gestão da Educação na
Saúde (2003). Caminhos Para a Mudança da Formação e Desenvolvimento dos Profissionais de Saúde: Diretrizes para a Ação Política para Assegurar Educação Permanente no SUS. Brasília, DF, Brazil.

13. Campos GWS (1992). Reforma da Reforma: Repensando a Saúde. Editora Hucitec, São Paulo, SP, Brazil.

14. World Health Report (2000). The World Health Organization page [http://www.who.int/whr/]. Accessed January, 2002.

15. Montes GS (2000). Distribution of financial resources according to the productivity (determined by bibliometrics) in the medical research laboratories of the Hospital das Clínicas da Faculdade de Medicina da Universidade de São Paulo. Revista Medica de Chile, 128: $431-436$. 